\title{
Immediate and Intermediate Results of Patent Ductus Artriosus Transcatheter Closure in Kurdistan (Multicenter Experience)
}

\author{
Aso F. Salih', Abass A. Al-Rabaty², Zuhair I. Al-Nasiry ${ }^{3}$ \\ ${ }^{1}$ Department of Pediatrics, School of Medicine, Faculty of Medical Sciences, University of Sulaimani, Kurdistan, \\ Iraq \\ ${ }^{2}$ Department of Pediatrics, School of Medicine, Hawler Medical University, Hawler, Iraq \\ ${ }^{3}$ Erbil Cardiac Center, Kurdistan, Iraq \\ Email: asofaek@hotmail.com, abasalrabaty@gmail.com, zuhair.alnasiry@gmail.com
}

Received 30 June 2015; accepted 19 May 2016; published 24 May 2016

Copyright $\odot 2016$ by authors and Scientific Research Publishing Inc.

This work is licensed under the Creative Commons Attribution International License (CC BY). http://creativecommons.org/licenses/by/4.0/

(c) (i) Open Access

\section{Abstract}

Background: Patent Ductus Artriosus (PDA) is abnormal vascular communication between aorta and pulmonary artery and it is a common congenital heart anomaly seen in pediatric practice forming $5 \%-10 \%$ of all congenital heart defects. A retrospective study aims to review our experience and determine the efficacy and safety of transcatheter PDA closure in different age groups and has the procedure replaced the conventional surgical closure of the PDA in the majority of the cases. To assess the results and outcomes of early experience, transcatheter closure of patent ductus Arteriosus in all three cardiac centers in Kurdistan, using the Amplatzer Duct Occluder type I and II (ADO), and Cook coil for the first time in Kurdistan are analyzed. Patients \& Methods: A total of three hundred and nine patients which included 228 females $\& 81$ males were diagnosed to have PDA, between March 2008 to February 2011 in all three cardiac centers in Kurdistan, namely Hawler, Sulaimani and Duhok cardiac centers, where they underwent transcatheter closure of the PDA with ADO type I and II. The common age on closure was 1 - 5 years old (range 5.5 months old to 32 years old), and weight ranged from $6 \mathrm{~kg}$ to $58 \mathrm{~kg}$. We retrospectively analyzed medical records, echocardiography, angiographic and hemodynamic data and follow-up results of the patients. Patients included in the study were according to standard recommendation for transcatheter closure of PDA, and in any age they should be above 6 kilograms with exclusion of cases with pulmonary hypertension and interrupted IVC. Results: Among 309 cases did catheterization procedures, the ratio of female to male ratio was 2.6:1 and the age of doing PDA closure at time of procedure was between 5.5 months old to 33 years old, the mean age was $6.3 \pm 6.5$ years old and the weight ranges between $6 \mathrm{~kg}$ and $58 \mathrm{~kg}$, mean of $11.5 \pm 7.5 \mathrm{~kg}$. The most commonly used device 
was Amplatzer I PDA device with high closure success rate of $97.1 \%$ after 6 and 12 months followup and the first case of Amplatzer II PDA Device closure done in Iraq and Kurdistan. There was immediate \& complete closure in 271 on angiography. Complication was noted as embolized PDA device to Right Pulmonary Artery (RPA) in two patients, one of them retrieved by cath and other one by surgery. Conclusion: Transcatheter Amplatzer duct occluder is safe and effective in closing PDA in most patients with PDA even large as much as $10 \mathrm{~mm}$ and the advantage of new Amplatzer PDA II device allows small delivery sheath in which it can be done for children with less than $6 \mathrm{~kg}$ with fewer complications. Disadvantage is that it cannot close more than $6 \mathrm{~mm}$ PDA.

\section{Keywords}

Patent Ductus Artriosus, Catheterization, Amplatzer Device, Embolization, Kurdistan

\section{Introduction}

PDA is a common congenital heart anomaly seen in pediatric practice forming $5 \%$ - $10 \%$ of all congenital heart defects [1].

It is nearly two times more common in female than in male. The duct can also vary considerably in its shape, as a result it categorizes according to Krinchenko angiographic classification to the following:

Type A: where the constriction localized at the pulmonary end of the ductus with well-formed aortic ampulla and this category is the commonest one.

Type B: (Window type) where there is constriction at aortic end and the ductus is wide and short and it blends with pulmonary artery.

Type C: (Tubular type) where the ductus is long and without constriction.

Type D: (Complex type) in which the ductus at least has two constrictions at pulmonary and aortic end.

Type E: (Elongated type) in which its shape is elongated with bizarre shape with remote constriction [2].

Study of a large number of angiograms from patients with persistently patent ducts undergoing interventional closure at the Hospital for Sick Children, Toronto showed that the most frequent pattern was to find a constriction at the pulmonary end of the duct (Type A) [2] [3]. This pattern was seen in two-thirds of cases. In just under one-fifth, a constriction found at the aortic end of the duct (Type B), and in just under one-tenth, the lumen was unrestricted (Type C). In just under one twentieth, there was a constriction at both ends (Type D), whilst the remaining patients showed bizarre patterns not lending themselves to classification (Type E) (Figure 1).

Most patients are asymptomatic, and the lesion is recognized with detection of the characteristic murmur. Children with large shunts may fail to thrive, have trouble with feeding during infancy, and frequently suffer recurrent infections of the upper respiratory tract.

There is retarded growth in about one-third of children. The continuous or machinery murmur of the uncomplicated persistent duct is best heard in the left infraclavicular area, although it is occasionally maximal at the third left interspaced (Gibson, [4] [5]).

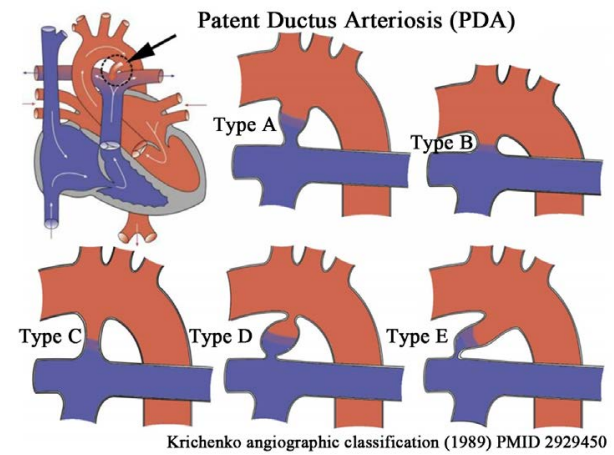

Figure 1. The variation in morphology of the arterial duct noted from angiograms taken prior to interventional closure at the Hospital for Sick Children, Toronto [2] [3]. 
For Patent Ductus Arteriosus (PDA) which is a common type of congenital heart disease [6], the closure with the use of an Amplatzer Duct Occluder (ADO) has been an excellent therapeutic option [7]-[9].

Portsmann et al. [10] [11] reported the first transcatheter closure of the Patent Ductus Arteriosus (PDA) in 1971.

Complications of PDA include congestive heart failure, repeated chest infections, pulmonary hypertension, and an increased risk of infective endocarditis. Transcatheter closure of PDA has largely replaced surgical ligation in different age groups [12].

\section{Aim of the Study}

The aim was to evaluate the short or immediate and intermediate results of PDA closure in three centers of Iraqi Kurdistan, using a new Amplatzer device made by AGA Company, to show the safety and effectiveness of this kind closure.

\section{Materials and Method}

\subsection{Procedure}

From March 2008 to February 2011, 3 centers in three governorates in Iraqi Kurdistan. Enrolled a total of 309 patients into this study in a nonrandomized fashion, age between 5.5 months old to 33 years old, the mean age is (6.3 \pm 6.5 years old) and the weight range between $6 \mathrm{~kg}$ and $58 \mathrm{~kg}$, mean of $(11.5 \pm 7.5 \mathrm{~kg})$.

The procedures are done by different local and international operators. Patients had angiographic or echocardiographic evidence of a PDA and had body weight $6 \mathrm{~kg}$ and more.

The exclusion criteria were pulmonary vascular resistance above 8 indexed Wood's units or Rp/Rs (pulmonary vascular resistance divided by systemic vascular resistance), an additional non-cardiac abnormality that might affect health, inferior vena cava or pelvic vein thrombosis, sepsis or a history of repeated pulmonary infection or associated complex congenital heart disease.

Baseline noninvasive data were obtained by physical examinations, electrocardiography, echocardiography, and chest radiography. During cardiac catheterization, angiographic (i.e. contrast angiography in lateral and RAO to show the site, size and shape of the PDA) and hemodynamic data (i.e. Pressure in aorta and pulmonary artery) were obtained before and after closure.

The catheter was typically position in the descending aorta for this angiogram. Angiographic measurements of the ductus at its narrowest and widest segments, as well as its length, were made in the lateral plane.

Next, an end-hole catheter was passed prograde through the ductus to the descending aorta, and a guide wire was placed via this catheter, with its end in the descending aorta. An introducer delivery sheath was then exchanged trans-venous over this guide wire to the descending aorta.

An appropriate size device was screwed on the delivery cable, keeping the device immersed under saline to expel the trapped air. The device was then introduced into the sheath through a rigid loader. The device was gradually advanced into the descending aorta without rotating the delivery cable. Tile sheath was gradually retracted allowing the retention disk to open in the descending aorta. The sheath and the device were then pulled back as one unit until the retention disk was snug against the aortic end of the ampulla. While maintaining traction on the delivery cable, the sheath was withdrawn into the pulmonary artery thus deploying the device into the duct. With the device still attached to the cable, a descending aortogram was performed in lateral position to confirm the position of the device. Once proper device position was confirmed, the device was then released by rotating the delivery cable counter-clockwise using a pin vise. A repeat descending aortogram was performed 10 minutes after the release to assess the degree of residual shunt.

A device size of at least $2 \mathrm{~mm}$ larger than the smallest PDA diameter has, thus, been recommended by the manufacturer. A large margin should perhaps be considered for tubular ductus [13].

\subsection{The Device}

The Amplatzer duct occluder (AGA Medical Corporation, Golden Valley, MN) is a self-expandable, mushroomshaped device made from a 0.004-in thick Nitinol wire mesh. A thin retention disk $4 \mathrm{~mm}$ larger than the diameter of the device ensures secure position in the mouth of the PDA. The PDA is closed by induction of thrombosis, which is accomplished by the polyester fibers sewn into the device [14].

All the devices are cone-shaped and 7 - $8 \mathrm{~mm}$ in length, with a recessed screw. Sizes are given from larger to 
smaller diameter. The delivery system consists of a delivery cable, long Mullins-type sheath, loader and pin vise [14] (Figure 2).

With the new ADO II device (Figure 3 and Figure 4), closure of PDA via an arterial approach in this patient was done without difficulty. The ADO II device consists of a self expanding multi- layer nitinol wire braid with symmetric retention disks and an articulating connecting center waist. Both discs are $6 \mathrm{~mm}$ larger than the diameter of the connecting waist. The device contains no sewn-in polyester fabric, which decreases the profile. The symmetrical design of the device and the low profile delivery allowed the retrograde approach via the femoral artery in this patient. The connecting waist diameter of the device ranges from 3 to $6 \mathrm{~mm}$ and its length is available in 4 and $6 \mathrm{~mm}$. The device is also highly effective in occluding morphologically varied PDAs (Figure 3 and Figure 4).

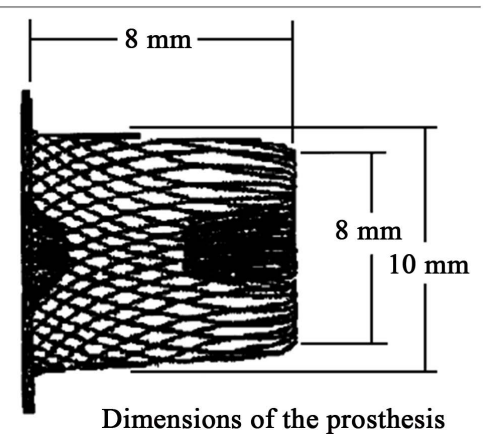

Figure 2. The Amplatzer duct occlude device. In this example of a 10/8 device, the "10" refers to the aortic end of the device and " 8 " refers to the pulmonary end. The retention disk on the aortic end is generally 4 - $5 \mathrm{~mm}$ larger in diameter than aortic ends diameter.

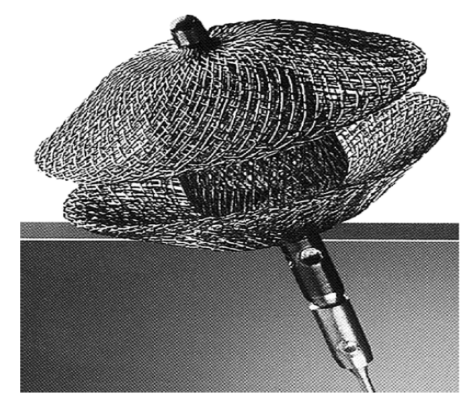

Figure 3. Amplatzer duct occlude II.

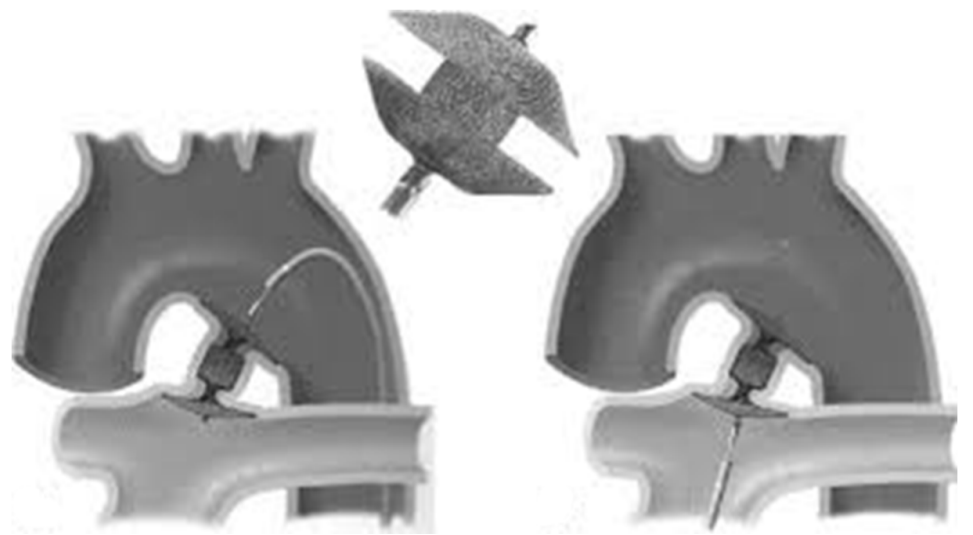

(a)

(b)

Figure 4. ADOII from venous and arterial approach. 
A 5 F and 6F size TorqVue low profile de livery catheter (AGA Medical, Golden Valley, MN) used for delivery of the device either introduced through arterial and even venous side.

Amplatzer duct occlude type II used for those cases when the closure by PDA I device cannot be used, where the ductus anatomy is long, and restrictive, and also can be used for infants easily because of the small sized long sheath in which available as $5 \mathrm{~F}$ and $6 \mathrm{~F}$, the other advantage is that it can be done on arterial side even in case we have no venous access.

\subsection{Follow up}

All patients were kept in-house for next 24 hours. They received two more doses of Ceftriaxone $(50 \mathrm{mg} / \mathrm{kg}$ body weight/dose) after the procedure. Each patient underwent complete 2-D echocardiography and Doppler interrogation looking for residual shunting and any evidence of obstruction to the flow in left pulmonary artery or descending aorta. All patients were reviewed clinically and with repeat 2-D echocardiography at 1 and 12 months.

\subsection{Approaches for Closure}

Different way of approaches of doing PDA closure was done apart from the ordinary way of doing it as follows.

\subsubsection{Difficulties}

In two of the cases when there was difficulty of doing crossing the PDA from pulmonary side, so we tried to cross from aortic side which is easier and their snaring it from pulmonary side, made a loop and then we advance the long sheath over it and then doing in the ordinary way (Figure 5 and Figure 6).

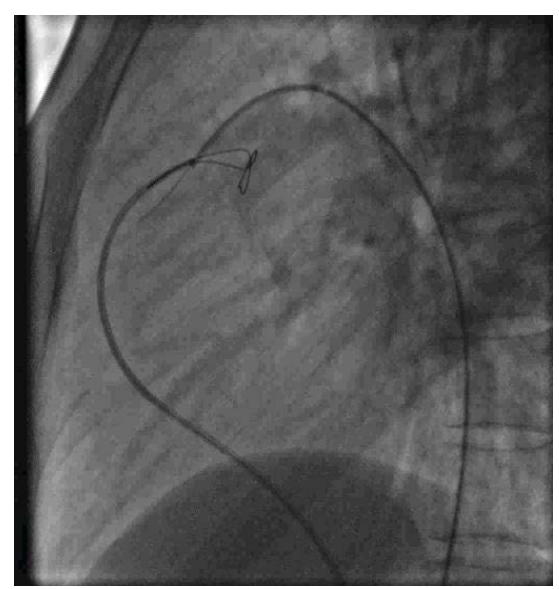

Figure 5. Snaring of the loop wire.

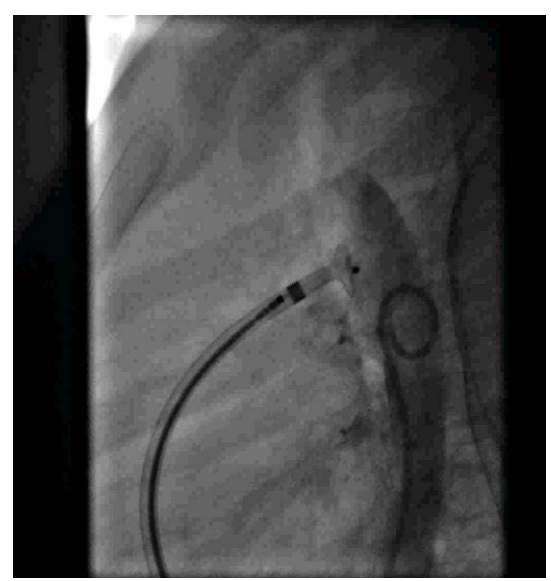

Figure 6. Angiogram with ordinary way. 


\subsubsection{PDAII Device Implantation}

During this case series study, we did the first six cases of PDA Amplatzer II device in Kurdistan. As far as we know this was the first attempt in Iraq with high success case, in which one of them done from aortic side (arterial side) without doing venous access (Figure 7).

\subsubsection{Type C PDA}

Two cases of type C PDA are done with Amplatzer I PDA device with tiny residual shunt, with encroachment of the device inside the duct and using bigger device (Figure 8).

\subsubsection{Embolization}

From embolized PDA to distal RPA, the device snared through a long sheath successfully and then put another bigger appropriate sized device (Figure 9).

\subsubsection{Special Technique}

Two cases are done with balloon occlusion of the PDA for evaluation of hemodynmic and saturations after balloon occlusion for the decision of closure by device and in another case for sizing the PDA for appropriate PDA device size (Figure 10).

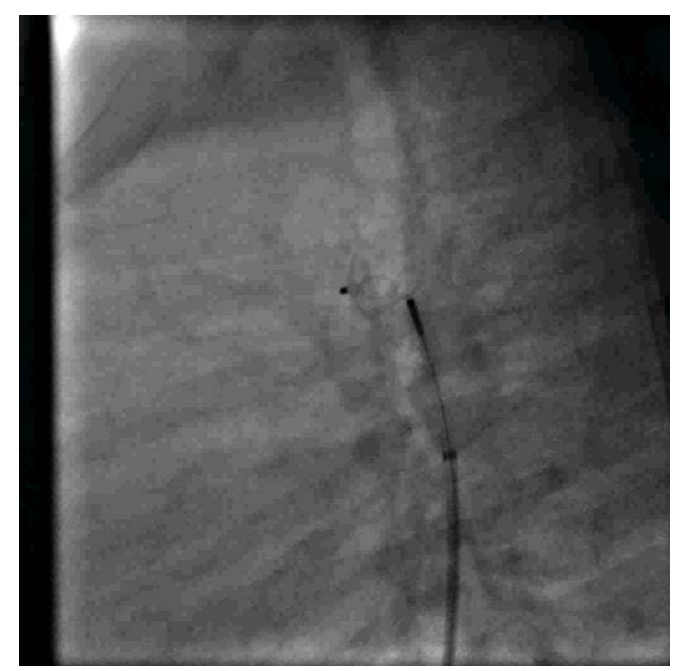

Figure 7. PDA II device closure (arterial approach).

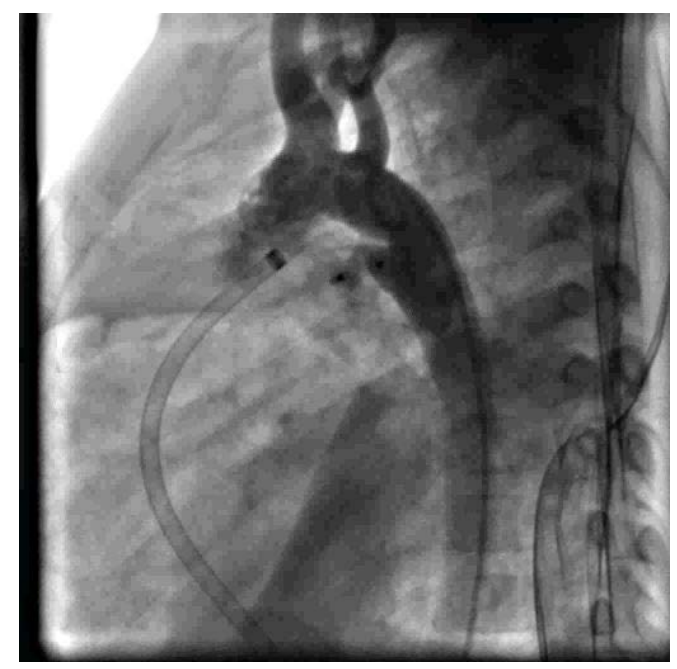

Figure 8. Residual shunt on aortic angiogram. 


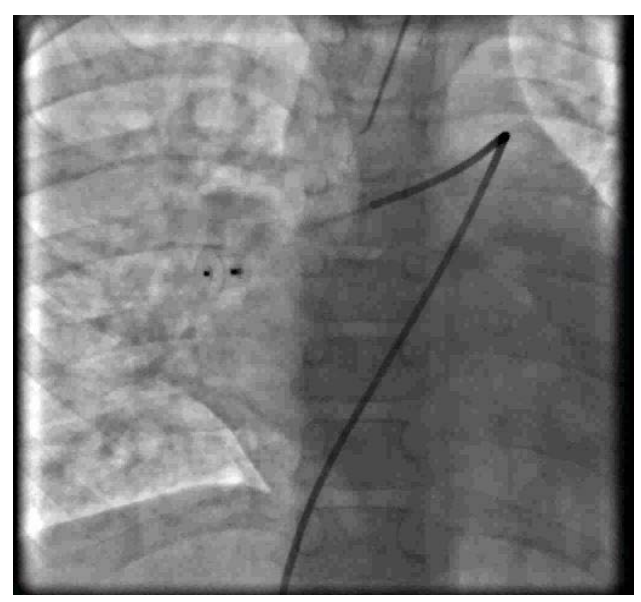

Figure 9. Embolized device in to right pulmonary artery.

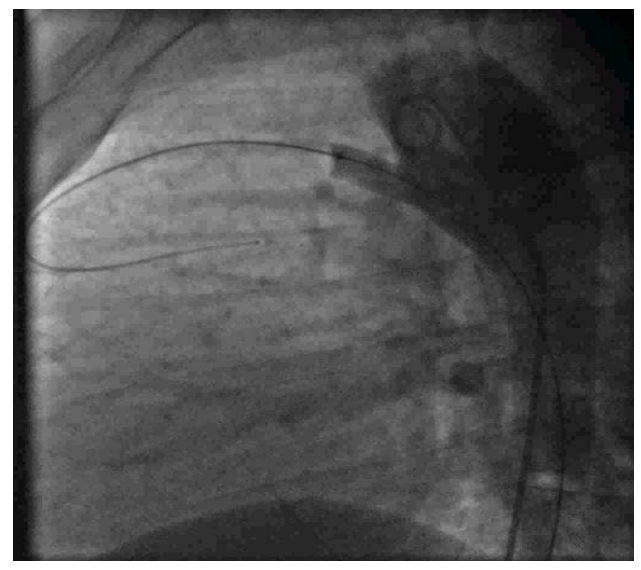

Figure 10. Balloon sizing of PDA during angiogram.

In some of the cases the lateral view being difficult to assess the sized and anatomy of the PDA, so we did RAO view to visualize the anatomy (Figure 11).

Before the release of the device, aortic pressure measurements should be carried out routinely. Protrusion into the aorta with a significant gradient requires removal of the device. However, protrusion into the left pulmonary artery results mainly in a redistribution of blood flow with no significant gradient. With growth of the child, the pulmonary arteries enlarge considerably, and this type of partial obstruction is expect to disappear at adolescence or long before, without clinical consequences [15]. Further clinical testing is required to determine any potential limitations for the use of the ADO in patients with small and especially very small PDAs.

\subsection{Limitation of the Study}

One of limitation of the study was about taking hemodynamic parameters before and after closure, because of either not taking or taking with inappropriate and incorrect way or not recording it on the cath reports just recorded for selected cases where pulmonary hypertension to be excluded.

Therefore, because of that in this study we are not concentrating on hemodynamic parameters.

Another limitation is that the experience in some of the cases makes the closure difficult, although complication was little.

\section{Results}

During the study period, 290 patients were taken to the cardiac catheterization laboratory for potential closure of the PDA. Of this group, 20 patients did not undergo implantation. 


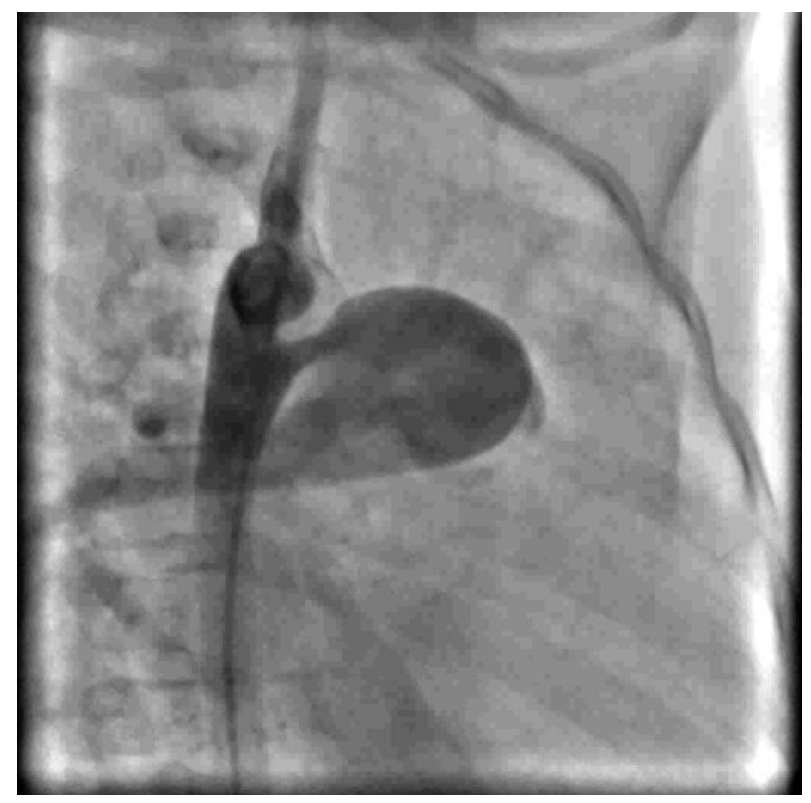

Figure 11. RAO view for visualization of the PDA.

A total of 270 patients did closure by PDA occluder successfully of the total number whom did catheterization procedure.

Among 290 total patients 214 (73.7\%) were female and 76 (26.3\%) were male, most of patients between 1 - 5 years (Table 1).

The most common used device for closure was Amplatzer AGA device I for closure of PDA which account of 97.4\% (Table 2).

Most common cause of failure of closure was anatomical type of PDA (Table 3) and the failure mostly ocdcure with type I (Table 4).

The most serious complication of PDA device closure is embolization of the device after closure, in Kurdistan case series we have 2 embolized device to right pulmonary artery branch as we retrieved one by snaring through a long Mullin sheath successfully, the other device embolized after discharging from hospital noted after the first visit after a month then patients underwent surgical ligation of PDA with removal of the device in another center.

One patients had significant pulmonary artery hypertension and elevated pulmonary vascular resistance and, therefore, did not undergo ductal closure in which confirmed by balloon occlusion of the duct where the pressure in pulmonary artery becomes supra systemic and the patient de-saturated.

One of the patients was not done because of LPA stenosis and later closure done by surgery with patching of LPA; another one was not done because of interrupted IVC with technical difficulties of this kind of approach.

Post closure angiography done and shows high rate of closure rate (Table 5).

\section{Discussion}

Among 290 patients involved in this study, the ratio of M:F was 1:2.8, which showed predominant of female gender; also in a study done in Saudi Arabia on 121 cases (76 females and 45 males) the result showed the predominance of female gender [12].

One of most important technical problems related to immediate post closure residual shunting across implanted device which relatively high incidence after closure by other PDA devices but its quit less common across Amplatzer device closure in current study in which we have 97.1\% complete closure rate closure rates also seen in a study done in Amman and Greece as they got 93\% closure rate at near the same average weight and ages. Foaming (trace angiographic residual shunt with no contrast jet) was seen in 85 cases account for 32\% of cases in which it disappears after 10-15 min of closure. Follow up closure rate by echocardiography after 1 month and 6-month follow shows 100\% closure rate but in the study done in Malaysia on 209 patients closure 
Table 1. Age distribution among PDA cases.

\begin{tabular}{|c|c|c|}
\hline Age & Patients & $\%$ \\
\hline Less 1 Year & 35 & 12.96 \\
\hline 1 - 5 Year & 99 & 36.66 \\
\hline 6 - 10 Year & 84 & 31.11 \\
\hline 11 - 15 Year & 22 & 8.14 \\
\hline 16 - 20 Year & 23 & 8.51 \\
\hline 21 - 25 Year & 4 & 1.5 \\
\hline 26 - 35 Year & 3 & 1.12 \\
\hline Total & 270 & 100 \\
\hline
\end{tabular}

Table 2. Frequencies of Amplatzer device sizes used for PDA closure.

\begin{tabular}{cccc}
\hline Amplatzer device size & Patient number & \% \\
\hline $\mathbf{5 / 4}$ & 20 & 7.6 \\
$\mathbf{6 / 4}$ & 74 & 28.03 \\
$\mathbf{8 / 6}$ & 92 & 34.84 \\
$\mathbf{1 0 / 8}$ & 42 & 15.9 \\
$\mathbf{1 2 / 1 0}$ & 24 & 9.1 \\
$\mathbf{1 4 / 1 2}$ & 8 & 3.03 \\
$\mathbf{1 6 / 1 4}$ & 4 & 1.5 \\
\hline
\end{tabular}

Table 3. The following table shows reason that either not feasible or can not do closure in 20 patients among 290 cases done in Kurdistan.

\begin{tabular}{ccc}
\hline Causes & No. & \% of Total cases \\
\hline Embolization & 2 & 0.68 \\
Type C PDA & 14 & 4.82 \\
Type B PDA + PHT & 1 & 0.34 \\
Type E PDA & 1 & 0.34 \\
Interrupted IVC with azygus continuation & 1 & 0.34 \\
PDA with LPA stenosis & 1 & 0.34 \\
Total & 20 & 6.89 \\
\hline
\end{tabular}

Table 4. Shows the number of cases in which not feasible to close or can not be close due to different kind of device types.

\begin{tabular}{cccc}
\hline Type of device & Success & Closure not done & Total \\
\hline Amplatzer PDA I & $264(92.98 \%)$ & $20(07.02 \%)$ & 285 \\
Amplatzer PDA II & $6(100 \%)$ & 0 & 6 \\
\hline
\end{tabular}

Table 5. Immediate Angiographic flow after closure with the device.

\begin{tabular}{ccc}
\hline Angiographic flow after closure & PDA I device & PDA II device \\
\hline Complete closure & $166(62.66 \%)$ & $4(66.66 \%)$ \\
Residual shunt & $14(5.34 \%)$ & 0 \\
Foaming & $85(32 \%)$ & $264.34 \%)$ \\
Total & 6 \\
\hline
\end{tabular}


rate after 6 months of device closure was 99\% [16]. And in another study done in USA as multicenter trial on 484 patients' shows 98\% closure rate after one year [13] and in study done in Yemen on 17 patients, complete closure was in all patients after 12 months of closure [14].

No complications like LPA stenosis and aortic obstruction observed although one case get mild gradient across descending aorta at aortic disc level with no complication on follow up.

No patient required blood transfusion; there were no femoral venous and arterial complications same as Yemeni experience [14].

An important advantage of the ADO is that it can be easily retracted into the delivery sheath and redeployed several times. This does not only reduce the risk for surgical or catheter removal of embolized devices but also reduces the cost obviating the introduction of a new device. With the exception of the detachable (controlled release) coils, all other devices are not repositionable, and once deployed, it is very laborious to reposition or to remove them [13] [17]. Misplacement of the ADO across the PDA occurred in 12 of our patients and was easily corrected by retracting the device into a large sheath and redeploying it.

No recanalization, migration, theromboembolic episodes, hemolysis or endocarditis noted after 12 months follow up.

Device Embolization: Embolization to the pulmonary artery in our cases was $0.68 \%$, possible cause may be due to inappropriate choice of device size in which it depend of personnel operator experience, in the study done in Malaysia embolization occur on 209 patients as a rate of 1.5\% with no adverse clinical and hemodynamic effects [16], also In USA trial [13] on 484 patients one embolized and retrieved and another embolized and then removed by surgery same as in our study in Kurdistan. In our study, we have no embolization to descending aorta.

The error lies in the choice of too small a device size, which in all cases led to the top part of the retention disc to slant forward midway in the ductus instead of sitting entirely on the rim of the ampula. The appearance of an indentation forming a bump on the superior wall of the ductus in aortic side caused by the retention disc slanting forward towards the PA should be taken as an ominous sign of the likelihood of embolization (Figure 12).

The mean fluoroscopy time for this study was 6.13 min as compared with other study done in Greece and Amman on 43 patients in which mean floro time was 7.9 min [17], also in study in Yemen on 17 patients mean fluoroscopy time was 13.7 minutes [14] and another study done in USA 0n 484 patients was 7.1 min [13].

The above results on floro in our study may be due to the following points:

1) The operator experience because of the large bulk of patients.

2) Mostly the operators does not stick to rules, mean they are not doing the procedure according to protocols and it may be one of the causes of short floro time.

In contrast to the preliminary work of Masura et al. [8], in this study, we successfully closed PDAs up to 10 $\mathrm{mm}$ and even $12 \mathrm{~mm}$ in diameter as in study done in Yemen, they did 10 and 12mm PDA size closure done with Amplatzer device [14].

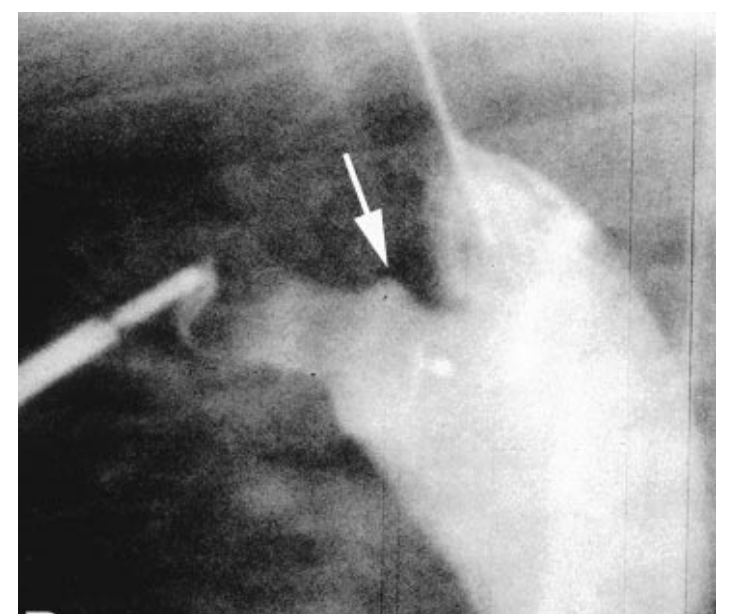

Figure 12. Small device placement before embolization, see the bump. 


\section{Conclusions}

From our experience in Kurdistan study, we conclude that PDA closure with Amplatzer Type I and II and coil devices are safe and effective for treating patients with these different kinds of PDA morphologically.

Experience plays a major role in the proper choice of device type and size which greatly influence the outcome of the procedure, this is crucial to minimize the complications.

In addition, we conclude that the PDA experience closure of PDA in Kurdistan becomes advanced and has results and outcome like others in advancing countries.

\section{Recommendations}

From our results of Kurdistan in all three centers, we recommend that PDA in different kinds and shapes can be effectively treated by Amplatzer device type I.

Amplatzer PDA device II for those PDAs with long restrictive shape cannot be closed by ordinary Amplatzer I device.

We recommend routinely taking hemodynamics before and after PDA closure for all cases and register them on cath report paper for proper registration and follow up.

\section{Compliance with Ethical Standards}

I declare that I have no conflict of interest.

Informed consent was obtained from all individual participants included in the study.

\section{References}

[1] Radhakrishnan, S., Marwah, A. and Shrivastava, S. (2001) Non-Surgical Closure of Large Ductus Arteriosus Using Amplatzer Duct Occluder Feasibility and Early Follow-Up Results. Indian Journal of Pediatrics, 68, 31-35. http://dx.doi.org/10.1007/BF02728854

[2] Krichenko A., Benson L.N., Burrows, P., Möes, C.A.F., McLaughlin, P. and Freedom, R.M. (1989) Angiographic Classification of the Isolated, Persistently Patent Ductus Arteriosus and Implications for Percutaneous Catheter Occlusion. American Journal of Cardiology, 63, 877-880. http://dx.doi.org/10.1016/0002-9149(89)90064-7

[3] Hornblad, P.Y. (1969) Studies on Closure of the Ductus Arteriosus: IV. Embryological Observation of the Ductus Arteriosus in the Guinea Pig, Rabbit, Rat and Mouse. Acta Physiologica Scandinavica, 76, 49-57. http://dx.doi.org/10.1111/j.1748-1716.1969.tb04449.x

[4] Gibson, G.A. (1906) A Clinical Lecture on Persistent Ductus Arteriosus. Medical Press and Circular, May 30th, 572-574.

[5] Tynan, M. (2003) The Murmur of the Persistently Patent Arterial Duct, or "The Colonel Is Going to a Dance”. Cardiology in the Young, 13, 559-562.

[6] Schneider, D.J. and Moore, J.W. (2006) Congenital Heart Disease for the Adult Cardiologist: Patent Ductus Arteriosus. Circulation, 114, 1873-1882. http://dx.doi.org/10.1161/CIRCULATIONAHA.105.592063

[7] Masura, J., Kevin, P., Thanopoulos, B., et al. (1998) Catheter Closure of Moderate- to Large-Sized Patent Ductus Arteriosus Using the New Amplatzer Duct Occluder: Immediate and Short-Term Results. Journal of the American College of Cardiology, 31, 878-882. http://dx.doi.org/10.1016/S0735-1097(98)00013-8

[8] Masura, J., Tittle, P., Gavora, P. and Podnar, T. (2006) Long-Term Outcome of Transcatheter Patent Ductus Arteriosus Closure Using Amplatzer Duct Occluders. American Heart Journal, 151, 755e7-755e10.

[9] Pass, R.H., Hijazi, Z., Hsu, D.F., Lewis, V. and Hellenbrand, W.E. (2004) Multicenter USA Amplatzer Patent Ductus Arteriosus Occlusion Device Trial. Initial and One-Year Results. Journal of the American College of Cardiology, 44, 513-519. http://dx.doi.org/10.1016/j.jacc.2004.03.074

[10] Porstmann, W., Wierny, L. and Warneke, H. (1967) Closure of the Persistent Ductus Arteriosus without Thoracotomy. German Medical Monthly, 12, 259-261.

[11] Porstmann, W., Wierny, L., Warnke, H., Gerstberger, G. and Romaniuk, P.A. (1971) Catheter Closure of Patent Ductus Arteriosus: 62 Cases Treated without Thoracotomy. Radiologic Clinics of North America, 9, 203-218.

[12] Azhar, A.S., Abd El-Azim, A.A. and Habib, H.S. (2009) Transcatheter Closure of Patent Ductus Arteriosus: Evaluating the Effect of the Learning Curve on the Outcome. Annals of Pediatric Cardiology, 2, 36-40.

[13] Pass, R.H., Hijazi, Z., Hsu, D.T., Lewis, V. and Hellenbrand, W.E. (2001) Multicenter USA Amplatzer Patent Ductus 
Arteriosus Occlusion Device Trial: Initial and One-Year Results. Journal of the American College of Cardiology, 44, 513-519.

[14] Al-Motarreb, A., Al-Hammadi, M. and Shamsan, M. (2006) Percutaneous Transcatheter Closure of Patent Ductus Artiosus Using Amplatzer Duct Occlude: First Yemeni Experience. Heart Views, 7, 101-104.

[15] Carey, L.M., Vermillon, R.P., Shim, D., Lloyd, T.T., Beekman III, R.H. and Ludomirsky, A. (1996) Pulmonary artery size and flow disturbances after patent ductus arteriosus occlusion. American Journal of Cardiology, 78, 1307-1310. http://dx.doi.org/10.1016/S0002-9149(96)00619-4

[16] Bilkis, A.A., Alwi, M., Hasri, S., Haifa, A.L., Geetha, K., Rehman, M.A. and Hasanah, I. (2001) The Amplatzer Duct Occlude: Experience in 209 Patients. Journal of the American College of Cardiology, 37, 258-261. http://dx.doi.org/10.1016/S0735-1097(00)01094-9

[17] Thanopoulos, B.D., Hakim, F.A., Hiari, A., Goussous, Y., Basta, E., Zarayelyan, A.A. and Tsaousis, G.S. (2000) Further Experience with Transcatheter Closure of the Patent Ductus Arteriosus Using the Amplatzer Duct Occlude. Journal of the American College of Cardiology, 35, 1016-1021. http://dx.doi.org/10.1016/S0735-1097(99)00626-9

\section{List of Abbreviations}

$\mathrm{ADO}$

IVC

LPA

PDA

PHT

RPA
Amplatzer dusct occlude

Inferior vena cava

Left pulmonary artery

Patent ductus artriosus

Pulmonary hypertension

Right pulmonary artery 